of voyages of discovery made during antiquity and the middle ages, as far as Magellan's first voyage round the globe, will be shortly published by Herr Spamer of Leipzig. It will contain some 100 illustrations, besides maps, charts, \&c.

\section{CRITICAL TEMPERATURE OF ETHYLENE}

M AMAGAT (Compt.rind. ${ }^{x}[1879]$, lxxxix. p. 437, corrected M. Beiblätter [1880], iv. p. 19) has submitted hydrogen, oxygen, nitrogen, air, carbon monoxide, methane, and ethylene at temperatures from $18^{\circ}$ to $22^{\circ}$ to pressures ranging between 28 and $43 \mathrm{I}$ atmospheres, and finds that, except for hydrogen, the product $p v$ first diminishes and then increases as $p$ increases, the most marked case being that of ethylene, for which the values of $p v$ at $3 I^{*} 58$, $84 \cdot 16,398 \cdot 71$ atmospheres are proportional to $2 \cdot 29$, I, $3^{\prime} \mathbf{1} 3$ respectively. Dr. van der Waals deduced this general peculiarity theoretically in 1873 , and showed that its markedness is the greater, the less the temperature of compression exceeds the critical temperature: concluding, therefore, that for ethylene the critical temperature is not far belo:v $18^{\circ}$, as M. Amagat has also surmised, he has recently (Meded. der k, Akad. van Wetenschappen in Amsterdam, Mei 1880) ${ }^{2}$ determined it directly by a Cailletet compression-apparatus, finding it to be $9^{\circ} \cdot 2$, and the critical pressure 58 atmospheres.

On p. 55 of his dissertation "Over de Continuiteit van den Gas- en Vloeistoftoestand" (Leiden, 1873), van der Waals finds the characteristic equation of a gas in the form-

$$
\left(p+\frac{a}{v^{2}}\right)(v-b)=R(\mathrm{I}+\alpha t),
$$

where $a, b, R$ are constants and $\alpha$ the coefficient of expansion, and on p. $79 \mathrm{et} \mathrm{seq}$. it is shown that at the critical temperature all three values of $v$ given by this equation, which may be written

$$
v^{3}-\left\{b+\frac{R(\mathrm{I}+a t)}{p}\right\} v^{2}+\frac{a}{p} v-\frac{a b}{p}=0,
$$

are equal : hence, if $V$ is put for this common value of $v$, and $T, P$ for the corresponding values of $t, p$, i.e. for the critical temperature and pressure, the theory of equations gives

whence

$$
{ }_{3} V=b+\frac{R\left(\mathrm{I}+a T^{1}\right)}{P}, 3 V^{2}=\frac{a}{P}, \quad V^{3}=\frac{a b}{P},
$$

$$
P=\frac{a}{27 b^{2}}, \quad V=3 b, P V=\frac{a}{9 b}, \mathbf{I}+\alpha T=\frac{8 a}{27 b R^{\prime}}
$$

and also

$$
a=3 P V^{2}, \quad b=\frac{1}{3} V, R=\frac{\mathrm{s}}{3} \frac{P V}{\mathrm{I}+\alpha T^{2}} .
$$

The minimum value of $p v$ at any temperature $t$ may be de ermined in the ustal way by $\frac{d \cdot p v}{d v}$ being equated to zero, and, if $p^{\prime}, v^{\prime}$ are written for the corresponding values of $p, v$, there resul $v^{\prime}=\frac{V}{3(\mathrm{I}-\tau)}, p^{\prime}=27(\mathrm{I}-\tau)(2 \tau-\mathrm{I}) P, p^{\prime} v^{\prime}=2(2 \tau-\mathrm{I}) P V$, where

$$
\tau^{2}=\frac{b R(\mathbf{I}+a t)}{a}=\frac{8}{27} \frac{\mathbf{I}+a t}{\mathbf{I}+a T} .
$$

Thus a minimum value of $p v$ exists only when

$$
\text { I }>\tau>\frac{1}{2} \text {, }
$$

i.e. only at temperatures that lie between

$$
\frac{a}{b R \alpha}-\frac{1}{\alpha} \text { and } \frac{a}{4 b R \alpha}-\frac{\mathbf{I}}{\alpha}
$$

If $p_{1}$ represents the pressure of the gas when occupying unit volune at $t$, then

$$
\left(p_{1}+a\right)(\mathbf{I}-b)=R(\mathbf{I}+a \cdot t),
$$

and, $p_{1}$ being the value of $p v$ in this initial state, the markedness of the minimum value of $p v$ is greater the less

$$
\frac{p^{\prime} v^{\prime}}{p_{1}} \text { or its equivalent } \frac{(\mathrm{I}-b)(2 \tau-\mathrm{I})}{\tau^{2}-b(\mathbf{I}-b)} \text {, }
$$

that is, since the sign of the $t$-differential coefficient of this expression is the same as that of $(\tau-b)(\mathrm{r}-b-\tau)$, the less $t$, provided that

$$
\text { I }-b>\tau>b \text {, }
$$

I Since the following was written, M. Amagat has published further results, which do not however affect its main point.

${ }_{2}$ Mr. Dickson seems to have independently discovered (Phil. Mag. for July, x880) the principles laid down by Dr, van der Waals in his above mentioned dissertation, pp. $79^{\circ} 93$, which is not sufficiently known in England or that the temperatures lie between

$$
\frac{a(\mathrm{I}-b)^{2}}{b R \alpha}-\frac{\mathbf{I}}{\alpha} \text { and } \frac{a b}{R \alpha}-\frac{\mathbf{I}}{a} \text {. }
$$

If $v$ represents the volume of the mass of gas which occup: $s$ unit volume at $0^{\circ}$ under unit pressure, then

$$
R=(\mathrm{r}+a)(\mathrm{I}-b)
$$

as is taken in the following calculations.

In the case of ethylene van der IVaals' experiments give $T=9.2$ and $P=58$ : hence, by the above relations with $\alpha=0.00367$,

$$
\frac{a}{b(\mathbf{I}+a)(\mathbf{x}-b)}=3.489, \frac{a}{b^{2}}=1566,
$$

which lead to a cubic equation that gives

$$
a=0.00786, b=0.00224, R=1 \cdot 0056 \text {, }
$$

so that the characteristic equation is

$$
p=\frac{0.0037(272 \cdot 5+t)}{v-0.00224}-\frac{0.00786}{v^{2}},
$$

\begin{tabular}{|c|c|c|c|c|}
\hline$p$ & & $\begin{array}{c}p v \\
\text { observed. }\end{array}$ & & $\begin{array}{c}p v \\
\text { calculated. }\end{array}$ \\
\hline $31 \cdot 58$ & $\ldots$ & 0.914 & $\ldots$ & \\
\hline 45.80 & $\ldots$ & $0.78 \mathrm{I}$ & $\ldots$ & 0.782 \\
\hline $59 \cdot 38$ & $\ldots$ & $0.522^{* k}$ & $\ldots$ & 0.624 \\
\hline $72 \cdot 86$ & $\ldots$ & 0.416 & $\ldots$ & 0.387 \\
\hline $84 \cdot 16$ & $\ldots$ & 0.399 & $\ldots$ & 0.392 \\
\hline $94^{\circ} 53$ & $\ldots$ & 0.413 & $\ldots$ & 0.414 \\
\hline I $10^{\circ} 47$ & $\ldots$ & 0.454 & $\ldots$ & 0.456 \\
\hline 133.26 & ... & 0.520 & $\ldots$ & 0.520 \\
\hline 176.01 & $\ldots$ & 0.643 & $\ldots$ & 0.642 \\
\hline $233^{\circ} 5^{8}$ & $\ldots$ & 0.807 & $\ldots$ & 0.905 \\
\hline $282^{\circ} 21$ & $\ldots$ & $0.94 \mathbf{I}$ & $\ldots$ & 0.940 \\
\hline $329^{1} 14$ & $\ldots$ & 1.067 & $\ldots$ & I.067 \\
\hline $398 \cdot 71$ & $\ldots$ & I. 248 & $\ldots$ & $\mathrm{I} \cdot 254$ \\
\hline
\end{tabular}

the pressure being reckoned in atmospheres; hence too $V=0.0067$ and $P V=0.39$. Further, when $t=20$, the mean temperature in Amagat's experiments, $\tau=0.5547$, and thus by calculation $p^{\prime}=76 \cdot 25$, while Amagat's direct observations give $p^{\prime}=84$ approximately, so far justifying the the theory. The temperatures for whicl $p v$ has a minimum value range from $678^{\circ}$ to $-35^{\circ}$.

The intinate agreement between Amagat's experiments and van der Waals' formula (which is entirely independent of them) is shown by the following table, wherein the first column contains the pressures (expressed in atmospheres) employed by Amagat, the second his experimental values of $p v$ divided by 23500 , and the third the values of $p v$ calculated for $t=20$ from the formula :-

The only serious discrepancy occurs for $p=59^{\circ} 3^{8}$, and van der Waals accounts for this by supposing that in Amagat's table 12263 is misprinted for 15263 , so that the asterisked number should be 0.650 ; for by experiment he finds that the ratio of the values of $p v$ for $p=45^{\circ} 80$ and $p=59^{\circ} 38$ is $x \cdot 26$ (the calculated ratio being $\mathbf{I}^{\cdot 25}$ ), while Amagat's actual numbers give $I \cdot 50$, but, when corrected, $x \cdot 20$.

For methane the equation of van der Waals' form that best satisfies Amagat's experimental values has for constants $a=10^{6} \times 2^{\circ} 9, b=53, R=25525$, if $t=20, \alpha=0.00367$, pressures being measured in metres of mercury, and this gives $-99 \frac{1}{2}^{\circ}$ for the critical temperature and $50 \frac{1}{3}$ atmospheres for the critical pressure. The constants have large values here, for, as calculation shows, the mass of the gas considered is about $24 \frac{1}{3}$ grams, which would occupy, at $0^{\circ}$ under one atmosphere, about 33518 c.c.

This discussion-with the numbers recalculated-by Dr, van der Waals of M. Amagat's experiments in connection with the critical temperature is here reproduced, together with the brief résumé of his theory (which has not hitherto appeared in an English dress), for ready application in other cases.

$$
\text { September } 17
$$

ROBERT E. BAYNES

\section{UNIVERSITY AND EDUCATIONAL INTELLIGENCE}

Cambridge. - The Natural Science Tripos Class List has just been issued. There are eight names in the first class, eight in the second, and fifteen in the third. Of those in the first class three attain their first class for Physics and Chemistry, viz. : Fleming, St. John's (distinguished in Physics) ; S. L. Hart, St. John's, and Heycock, King's. Two attain their first class for 
Botany: Hillhouse, Trinity, and Hoffmeister, Caius (distinguished); and three for Zoology, Anatomy, and Physiology: Caldwell, Caius; Pigeon, Christ's ; and Shaw, Sidney.

Mr. J. A. Fleming, B.A., of St. John's, has been appointed to the new post of Demonstrator of Mechanism and Applied Mechanics; Mr. Flening is a distinguished graduate of London University, as well as having attained distinction in Physics, with first class honours in the Natural Science Tripos of this year.

Mr. J. Y. Lister, B.A, of St. John's College, has been appointed Demonstrator of Comparative Anatomy, in place of Mr. A. C. Haddon, who has been appointed to the Professor ship of Zoology and Comparative Anatomy in the Royal College of Science, Dublin, vacated by Prof. Bridge.

Mr. A. H. Cooke, B.A., Fellow of King's College, has been appointed Curator of the Zoological Museum.

\section{SCIENTIFIC SERIALS}

Annalen der Physik und Chemie, No. II.-Magnetic researches, by F. Auerbach.-New researches on magnetism, by C. Baur.-On so-called polar induction, by E. Riecke.-Determination of the absolute velocity of current electricity from Hall's phenomenon, by A. v. Ettingshausen.-Method of calibration of a wire for galvanic measurements, by W. Giese. -Action of gases and vapours on the optical properties of re. flecting surfaces, by P. Glan.-On a new interference-photometer, by Fr. Fuchs.--Influence of the density of gases on their conduction of heat, by A. Winkelmann.-Currents of liquids resulting from unequal temperature within them, by $\mathrm{A}$. Oberbeck. - Theory of the interference-phenomenon presented by dichroïtic crystal-plates cut at right angles to the axis, by E. Ketteler.On the polarisation of diffracted light, by M. Kethy.-On changes produced in the spark and brush phenomena by coverings of the electrodes, by W. Holtz.-On atmospheric refraction of sound rays, by A. Kneser.-Double-acting mercury-pump without cock, by $F$. Neesen.-Alteration of Riidorff's absorptionhydrometer, by the same - Reply to a note by O. E. Meyer, by L. Boltzmann.-Remarlss on U. Duihring's paper on the law of corresponding boiling temperatures, by A. Winkelmann.

\section{SOCIETIES AND ACADEMIES LONDON}

Zoological Society, December 14.--Prof. W. H. Fowler, LL.D., F.R.S., president, in the chair.-Mr. Sclater exhibited and made remarks on a skin of a brown female of Pauxis galeata, formerly living in the aviary of the late Mr. G. Dawson Rowley, F.Z.S.-Dr. A. Giinther, F.R.S., exhibited and made remarks on a skin of a new species of Rhynchocyon from Eastern Africa, discovered by Dr. Kirk. - Prof. T. H. Huxley, F.R.S., read a paper on the application of the laws of evolution to the arrangement of the Vertebrata, and more particularly of the Mammalia. -Lieut. Col. H. H. Godwin-Austen, F.R.S., read a paper on the anatomy of Ferussacia gronoviana, Risso, from Mentone, pointing out its general relationship with Lovea tornatellina, Lowe, of Madeira, and with Ferussacia follicula, Gronov., from Algiers.-Mr. Arthur G. Butler read a paper on a second collection of Lepidoptera made in Formosa by Mr. H. E. Hobson. Thirty-three new species were found in this collection.- Mr. Oldfield Thomas, F.Z.S., read a paper containing the description of a new species of Reithrodor, obtained in Venezuela by the late Mr. D. Dyson, which was described as Reithrodon alstoni.-Dr. A. Günther read a paper containing notes on some rare reptiles and batrachians now or lately living in the Society's Gardens.

Physical Society, December II.-Prof. W. G. Adams in the chair.-New Members : Mr. W. R. Brown, Mr. T. Mightson, C.E.-Lieut. L. Darwin read a paper on the rate of loss of light from phosphorescent substances. His experiments were made at Chatham on Balmain's luminous paint, by comparing the intensity of the phosphorescent light with the light of a sun-burner; the luminous surface being kept cool by placing ice and water near, as a slight increase of temperature in the surface considerably increases the quantity of light given off in a certain space of time. The supply of light was communicated to the paint from a mirror reflecting sunlight. A table and a curve exhibited to the meeting showed the rate of loss found by Lieut. Darwin. It is independent of the original intensity of of the illumination. According to the curve the light diminishes very nearly in proportion to the square of the intensity of the light. In a report on the use of Balmain's paint in mines, it had been stated that the phosphorescence became brighter a few minutes after exposure in the dark; but the curve showed this to be an error, due probably to the fact that the eye become. more sensitive to light after being a few minutes in the dark. Mr. Pearsall emphasised the advantages of such a light in fiery mines. Prof. Guthrie inquired if the phosphorescent power grew weaker by time, and Lieut. Darwin instanced a specimen eighty years old to the contrary; but Dr. W. Crookes stated that these luminous substances give off sulphuretted hydrogen in damp air and deteriorate. If sealed in a vacuum they would not. Dr. Crookes remarked that in Balmain's patent it was stated that the phosphorescence died out sooner when exposed to a strong light for a short time than to a weak light for a longer time; but Lieut. Darwin thought this was explained by the slow decrease in the lower part of the curve when the phosphorescence became faint. Mr. R. J. Lecky mentioned that Evelyn in his Diary ( 1650 ) describes a phosphorescent powder as "bottling up" sunlight. Dr, Coffin inquired if short exposure to strong light was equivalent to long exposure to feeble light. Lieut. Darwin thought not.-Dr. C. R. Alder Wright read a full paper on the determination of chemical affinity in terms of electromotive force. $\mathrm{He}$ considered first the value of the B.A. unit of resistance, which from different experimenters might be taken as really I 005 earth quadrants per second, or not more than half per cent. out. Clark's element when carefully prepared was practically correct at $\mathrm{I} 457$ volts, and it kept constant for three or four months after being made, but deteriorated thenceforth some 3 per cent. in about two years. The deterioration was assisted by air, which could not be well exchnded by the paraffin cork, as it cracked. If sealed in a Sprengel vacuum the element lasted better. Joule's mechanical equivalent of heat $(J)$ he estimated at $42 \times 10^{6}$, or not over 1 per cent. greater than Joule's water value. The chief result of Dr. Wright's researches was the conclusion that the action of a current in electrolysis is to decompose the electrolyte into " nascent" products which evolve heat in changing into ordinary products of electrolysis. These nascent products may be the ultimate atoms composing the molecules of the ordinary products, and the heat is given out in these atoms coming together to produce molecules, say of oxygen and hydrogen in the case of water. A number of deductions from this theorem are verified by experiment. One of these is that no gas battery can give a higher E.M.F. than $\mathbf{1}^{\circ} 5$ volts. A result, not before published, is that the E.M.F. of a Daniell cell is a function of the current and is a maximum when the current is indefinitely small. The variation may amount to ro degrees. Therefore all methods of determining resistance by means of two currents of different strength are inaccurate. Dr. Wright's experiments also verified Faraday's law that conduction in an electrolyte is always accom. panied by electrolysis. Prof. Adams inquired if Dr. Wright had seen the letter of Prof. Rowland's assistant to the effect that Dr. Wright's former estimate of the ohm was on the wrong side of unity. He had been too busy to see it. Prof. Foster thought that the variation of E.M.F. in a cell with the current was to be expected, and was probably due to the slowness of diffusion. Dr. Wright thought diffusion would account for it. Dr. Lodge said that there was no way of measuring the resistance of a cell except by employing two currents of different strength, and therefore it was necessary to know the law of variation of E.M.F. with current strength. Dr. Wright stated that he had found two methods of proceeding with currents of the same strength. With regard to the deduction of Dr. Wright that no current passes without producing electrolysis, Mr. Walenn inquired if the ordinary law of solution held when there was no evolution of hydrogen, and was answered in the affirmative.-Prof. Guthrie cited the experiments of Mr. C. V. Boys and himself on the conductivity of liquids as an instance of a current passing without electrolysis, or if there was decomposition it was followed by instant recomposition. Dr. Wright thought there must be electrolysis in Dr. Guthrie's experiments (which were conducted by rotating a glass vessel filled with the liquid between the poles of a magnet, after Arago's experiment), because some two parts of the rotating vessel would be at different potentials, and a current would be set up in the liquid.-The Society then adjourned till after Christmas.

\section{PARIS}

Academy of Sciences, December I3.-M. Edm. Becquerel in the chair.-The following papers were read:-Solid and 